\title{
Cildo Meireles: a poética do desvio
}

Martha Telles*

http://dx.doi.org/10.22409/poiesis.1829.281293

RESUMO: Em Cildo Meireles, fazer arte implica a reflexão sobre as questões relacionadas à natureza do objeto de arte e seu modelo de significação. Ao indagar os limites da própria linguagem, a arte passa a ser pesquisada como um complexo processo que compreende o pensamento e a experiência sensível. Elaborados como verdadeiros puzzles, tais trabalhos articulam linguagens que entrelaçam cultura da política, economia, antropologia e história, sem jamais se deixar explicar totalmente por eles. A poética do desvio tematiza a constante redefinição do conceito de arte, momentos de transgressão em que as verdades da arte e do mundo são subvertidas.

PALAVRAS-CHAVE: Cildo Meireles, arte contemporânea, redefinição do conceito de arte, linguagem

ABSTRACT: In Cildo Meireles, art production implies reflection on the issues related to the nature of the art object and its model of meaning. When inquiring the limits of language itself, art begins to be researched as a complex process that comprises thought and experience. Elaborated as true puzzles, such works articulate languages that interweave the culture of politics, economics, anthropology and history, without ever being fully explained by them. The poetics of deviation thematizes the constant redefinition of the concept of art, moments of transgression in which the truths of art and of the world are subverted.

KEYWORDS: Cildo Meireles, contemporary art, redefinition of concept of art, language

\footnotetext{
* Martha Telles é Mestre e Doutora em História Social da Cultura (PUC-Rio), tendo realizado estágio PDEE na CUNY (City University of New York). Tem experiência em história da arte contemporânea, história da arte brasileira e sistema de arte. Atua como pesquisadora, professora e curadora. Desde então, vem publicando artigos, ensaios, resenhas e livros. E-mail: mtellesm@uol.com.br.
} 
Era uma vez uma coincidência que saiu a passeio em companhia de um pequeno acidente. Enquanto passeavam, encontram uma explicação, uma velha explicação, tão velha que já estava toda encurvada e encarquilhada, que mais se parecia com uma charada. -- História contada em Sylvie and Bruno, Lewis Carroll

Montar, desmontar jogos, desnaturalizar o sentido corrente da linguagem, inquirir poeticamente o que acreditamos ser o real são constantes na construção da arte de Cildo Meireles. Elaborados como verdadeiros quebra-cabeças, seus trabalhos articulam sutis deslocamentos em domínios como linguagem, história política, história da arte, literatura, matemática, física, geografia. Operam permanentemente com a ambiguidade, criam jogos sem regras previamente definidas, produzindo não-sentidos que acabam criando novos sentidos. São jogos para os quais o artista não propõe soluções, mas sim surpreendentes paradoxos. As transgressões dos princípios lógicos, tais como as reversões e inversões, e os contrassensos estruturam uma linguagem reflexiva e crítica sobre o fazer arte.

Esse caráter reflexivo de seus trabalhos guarda uma interlocução estreita com o legado de Marcel Duchamp, para quem a arte era uma forma de pensamento. Duchamp dessacraliza o espaço da arte ao conferir estatuto artístico a trabalhos como Porta-garrafas, de 1914. Faz prevalecer, assim, o ato de escolha, o ready-made, que se fundamentava em uma atitude de indiferença visual e deslocamentos de sentidos. Cildo Meireles retoma esse percurso com desvios e acréscimos, aprofundando questões como as do ready-made.

Em 1970, o artista inicia a série Inserções em Circuitos ideológicos, intervenções em suportes tais como cédulas monetárias, garrafas de refrigerantes, anúncios de jornais nas quais se propõe a investigar o conceito de circuito e as possibilidades de intervenção no processo de fazer arte. Nesses trabalhos, a lógica do ready-made duchampiano é subvertida. Aqui, a interferência no sistema de arte não se processa pelo fato de objetos industriais ingressarem no "espaço sagrado" das instituições de arte, mas sim por participarem da cadeia de informação do produto industrial. É o meio circulante das garrafas de Coca-Cola e do papel-moeda que promove a visibilidade dos mecanismos de circulação. Trata-se da elaboração de uma linguagem que evidencia a realidade social, de mais uma ação do artista no combate ao que se 
chamou de "a habituidade e o artesanato cerebral." (CAMERON, 2000) Tal linguagem é capaz de gerar uma resposta crítica que interfira no sistema de arte, cujo propósito é ir além da lógica do ready-made, além do curto-circuito do gesto histórico de deslocar um objeto industrial para o museu. São jogos de linguagem que devem fixar o conceito duchampiano, propondo indagações sobre o espaço da arte, o circuito.

As Inserções em circuitos ideológicos isolam e definem o conceito de circuito, valendo-se de um sistema preexistente de circulação. "O circuito é que se torna um ready-made, um graffiti (suporte) que circulava". (CAMERON, 2000) A retirada do circuito comercial de produtos comerciais de consumo industrial, como as garrafas de Coca-Cola, sua posterior alteração e reinserção no circuito, possibilitam a visibilidade do próprio circuito, agora como um ready-made. $\mathrm{O}$ isolamento e a fixação desse conceito operam um movimento dialético entre a consciência resultante da visibilidade do circuito e o conteúdo anestesiante dos sistemas de circulação de massa como a imprensa, o rádio e a televisão. São contrainformações capazes de despertar a consciência crítica do público, de abrir o debate sobre as questões que envolvem a linguagem visual. Se é verdade que o artista evoca o viés ético da arte ao reivindicar sua função social (CAMERON, 2000), talvez o que esteja realmente em jogo em Inserções em circuitos ideológicos seja a pergunta sobre o que é arte.

Assim como em Duchamp, para quem a arte não mais se definiria a partir de categorias de juízo estético, passando a ser tida como enunciados, os trabalhos de Cildo Meireles podem ser entendidos como um sistema de linguagem. Em suas palavras, "para cada nova ideia, uma nova linguagem". (MACIEIRA,1981, p. 113) Linguagens cujo sentido se produz no embate com os limites da cultura. Como escreveu o artista acerca da relação entre arte e cultura, "a interferência de Duchamp no sistema de arte foi do ponto de vista da lógica do objeto de arte, vale dizer, da estética. Qualquer intervenção hoje - uma vez que o que se faz tende a estar mais perto da cultura do que da arte - é necessariamente uma interferência política". (MACIEIRA, 1981, p. 113) Na idéia de circuito, a novidade encontra-se no fato de o objeto de arte passar a pertencer à ordem da linguagem, ao campo da cultura. Como linguagem, sua obra assume um modelo de significação para o qual o significado se define no seu uso social, em suas relações com o mundo. Em uma dialética entre a reflexividade conceitual e a carnalidade da experiência social, seus trabalhos são capazes de articular objetos, circunstâncias cotidianas e estruturas sociais da esfera pública e política da existência. Nesse sentido, é significante seu 
interesse por disciplinas como a antropologia, a história, a topologia e a economia, como se seu trabalho encontrasse possibilidade de existência nas fronteiras demarcatórias um tanto embaralhadas no território da arte e da cultura.

Cildo Meireles inicia sua trajetória no final dos anos 1960, momento em que a própria arte enfatizou a investigação crítica e teórica. Fazer arte, nesse contexto, implica a reflexão sobre as questões relacionadas à natureza do objeto de arte e do seu modelo de significação. Tratase da indagação dos limites da própria linguagem de arte que, nessa concepção, deveria ser investigada como um complexo processo que compreende o pensamento e a experiência sensível. Ao rever os conceitos de obra de arte, de artista e do papel do espectador, Cildo Meireles estrutura seu discurso de forma a questionar as certezas, fazendo verdadeiros puzzles linguísticos, deslocamentos que abalam os truísmos sobre nosso entendimento de arte.

Em tal redefinição, trabalhos como o Projeto cédula e o Projeto Coca-Cola propõem uma consciência crítica do fazer arte, colocando em xeque a noção de objeto de arte, de artista e de sistema de arte. Aqui, a proposta de dar visibilidade a uma prática social -os circuitos monetários e de distribuição de produtos industriais - contrapõe-se à concepção da produção artística definida como objeto singular, como o ideal de unidade da obra de arte. Tal artimanha subverte a ideia da existência de um espaço autônomo da arte, uma vez que é a arte que chega ao espectador, não o espectador às instituições de arte. É abandonada ainda a concepção de indivíduo-artista, ao elaborar-se um processo artístico no qual a autoria torna-se quase anônima. A partir da reflexão sobre o papel do artista-autor, será possível a redefinição das condições e do papel do espectador. Qual seria o papel possível para o artista? Um provocador capaz de gerar estranhamentos em situações específicas que se revelem nos atritos entre a linguagem e o real?

No mesmo Projeto Cédula, notas de dez cruzeiros e de um dólar são carimbadas com instruções para que quem as recebesse gravasse nelas "informações e opiniões críticas" e em seguida as devolvesse ao fluxo monetário. A ideia é provocar o senso crítico, romper com a naturalização do sentido. (CAMERON, 2000, p. 113) Aquele que receber as notas despertará para a ideia de que aquele dinheiro pertence a um circuito, poderá visualizar seus próprios limites, produzindo assim uma fricção no real convencionado pela linguagem. Ao colocar em evidência os dispositivos lógicos da arte, o espectador percebe a existência de tais mecanismos, participando criticamente de seu percurso processual. 
O Projeto Token (1971), em Inserções em circuitos antropológicos, dá instruções sobre como fazer fichas telefônicas utilizando caixas de fósforos vazias, gesso e argila. Aqui, importa menos a constatação da existência de circuitos e mais a ideia de Inserção como interferência no comportamento social, o que poderia deflagrar o movimento de subversão na cadeia de participação nos circuitos públicos em questão. A possibilidade da reprodução das fichas de telefone e ônibus garantiria o acesso aos sistemas de comunicação e de transportes como um agente participativo. A difusão do how make de um código, de uma senha de entrada ativa do sistema, ironiza a noção de exclusividade no processo criador, alterando o jogo de forças. Aquele que se aventurar a reproduzir as fichas estará abandonando o lugar contemplativo, conquistando um espaço participativo no processo artístico.

A inclusão do espectador no processo artístico é estratégia visando colocar em dúvida a noção de intencionalidade do artista. Em tal proposta, seria possível estabelecer um diálogo com a noção de "coeficiente artístico" de Duchamp. Nele, o artista francês detecta a falta de um elo na cadeia de reações que acompanham o ato criador. Tal falha representaria a inabilidade do artista em expressar integralmente sua intenção. O "coeficiente artístico" seria a arte em estado bruto, que necessitaria ser "refinada" pelo público, de tal sorte que o "o ato criador não é executado pelo artista sozinho; o público estabelece o contato entre a obra de arte e o mundo exterior, decifrando e interpretando suas qualidades intrínsecas e, desta forma, acrescenta sua contribuição ao ato criador." (DUCHAMP, 1975) O que está em discussão é a concepção do artista como responsável pelo processo artístico, no qual o objeto de arte aparece como um índice do ato de criação, cujas raízes se encontram na intenção de fazer a obra. A intencionalidade pode ser entendida como um tipo de acontecimento mental preexistente, inacessível à visão, mas que a obra testemunha posteriormente. Em Inserções em circuitos ideológicos, a ideia de intencionalidade do artista é confrontada com uma dimensão pública. A proposta é que o trabalho se revele por meio de uma prática social, na qual a autoria quase anônima e coletiva acaba devolvendo ao público o papel de estabelecer uma relação entre a obra de arte e o mundo. O artista atuaria como um provocador, um produtor dos estranhamentos necessários para suscitar o atrito na linguagem da arte.

\section{Desvios semânticos}

A relação entre imagem visual e frase verbal é artimanha comum a muitos dos trabalhos de Cildo Meireles que, assim como os de Duchamp, buscam criar espaços nos quais surjam 
novas relações entre palavra e imagem em que a ressignificação poética da realidade seja possível. São trabalhos como Dados (1970), Porta-bandeira (1981), Desaparecimentos (1982), Percevejo / Cerveja / Serpente (1980), em que o artista cria jogos entre a abstração das palavras e a materialidade da obra. Dados (1970) propõe um jogo circular de deslocamentos entre o título, a placa no estojo de joias e o "dado" dentro do estojo. A palavra "dado" pode ser entendida tanto como na acepção de objeto dos jogos lúdicos como na de informações fornecidas sobre determinado sistema. A circularidade é sugerida pela repetição da palavra "dado" e pela sua indicação de dupla acepção da palavra, assim como pela própria imagem do objeto.

É possível perceber uma analogia com a série Rrose Sélavy, em que Duchamp monta um disco giratório de modo que as frases homofônicas pareçam não chegar a um termo. Tal característica de circularidade engendra uma espécie de perplexidade, remetendo continuamente ao início da pergunta: por quê? (KRAUSS, 1998, p. 86), evitando, assim, a estrutura na qual o significado é resultado de uma solicitação ao objeto. De modo similar, em Dados a percepção circular indica que o significado não está unicamente atrelado ao objeto, mas se processa no espaço entre o título, o objeto e as inscrições na placa, portanto, na externalidade do discurso da linguagem. Nesse jogo entre o sensível e o conceitual, não é permitido ao espectador estabelecer uma relação causal com as impressões sensoriais do objeto, abalando suas convicções acerca do que acredita ser arte. É jogando com os limites formais e perceptivos da arte que um processo reflexivo é deflagrado, questionando nossas certezas acerca do real.

\section{Embaralhar o jogo, subverter as regras}

As inversões e reversões são constantes nas propostas de desmantelamento do sentido corrente da arte em Cildo Meireles. Trabalhos como Las brujas (1981) e Cruzeiro do Sul (1969/1970) põem em suspenso o bom senso, as verdades de sentido único, adotando a lógica do paradoxo, o qual afirma dois sentidos ao mesmo tempo. Em Las brujas, as cerdas de uma vassoura, tradicionalmente hirtas e de dimensões reduzidas em relação ao cabo, assumem a forma maleável de novelos que, ao se expandirem para além do lugar reservado ao objeto de arte, invadem o espaço destinado à circulação do espectador. Em um jogo de inversões e deslocamentos, o trabalho propõe a subversão da hierarquia nos tradicionais papéis do espectador e da obra. 
O paradoxo e a frustração da lógica convencional é poética em Cildo Meireles. As grandes escalas tornam-se ínfimas, como em Cruzeiro do Sul, na qual a imensidão de uma região imaginária cabe em um minúsculo cubo de $9 \mathrm{~cm}$. O cubo, metade, de madeira de carvalho, metade, de madeira de pinho, guarda a mitologia de uma região de dimensões infinitas por sua capacidade de produzir "lendas e fábulas e alegorias fantásticas". (CAMERON, 2000) A ínfima ocupação do espaço de Cruzeiro do Sul em relação às dimensões das instituições de arte produz uma estranheza que, ao expor sua "insignificância"(CAMERON, 2000), instaura espaço para questionamentos das convenções estabelecidas, das escalas hierárquicas no sistema cultural, mas especificamente do mundo das artes. Afinal, qual seria o lugar da experiência de arte no atual regime cultural no qual instituições de arte são cada vez mais inseparáveis do mercado de entretenimento e do turismo?

É criando sentidos propositalmente contraditórios que o artista produz sentidos inesperados, fundadores de sua poética. Em Estojo de geometria (Neutralização por oposição/ou por adição), (1977-1979), a soma, a adição resulta em perda, em decréscimo de potência. Nas obras, as quatrocentas lâminas de barbear estão empilhadas e atarraxadas com parafusos, o que castra seu potencial de causar danos. De objetos perfurantes, os dois pregos com as respectivas pontas fundidas ganham uma aparência bizarra, mas nada que sugira ação danificadora. Os dois cutelos, fundidos nas lâminas, perdem o valor de objeto cortante. É por meio dessa negação que se revela a capacidade de interferir nos sistemas estabelecidos, nas verdades hegemônicas, principalmente naquelas sustentadas exclusivamente pela percepção visual.

O uso de estruturas em paradoxos apresenta-se ainda como um artifício/estratégia de desarticulação do modelo de racionalidade fundamentado na dicotomia entre sujeito e objeto. Fazendo uso das contradições, inversões e reversões, o artista trama linguagens nas quais o espectador é convidado a transgredir o esquema apriorístico de tal concepção. Tais estruturas criam deslocamentos de significados nas quais é possível reencontrar um terceiro espaço de significação. Espaço esse em que o real é entendido como uma criação e recriação constante entre o homem e o mundo.

\section{Desvios espaciais}

No processo de inquirição de Cildo, a pergunta sobre o espaço revela-se essencial. Não há um espaço em si, nos diz o artista, ele é resultado de concepções humanas. Para formular 
essas questões, é importante desnaturalizar tal noção, criando estranhamentos, subvertendo o que pensamos ser a verdade do espaço. Suas reflexões nos informam, de saída, ser o espaço resultado das construções humanas, sujeito a novas elaborações. Espaços virtuais: cantos (1967/1968) inicia uma série de interrogações sobre tais verdades. As quinas do que se acredita ser uma sala doméstica ganham novos ângulos, rompendo com a noção de retas, ângulos, da geometria euclidiana. Sem tal geometria, não são possíveis as grades ortogonais da perspectiva clássica. A ideia é desestabilizar os sentidos, pôr em xeque a hegemonia da visão. O participante que esperava encontrar a familiaridade das coordenadas ortogonais geométricas, quinas formadas pelos ângulos de 90 graus, surpreendido com a subversão do teorema euclidiano é levado a experimentar uma situação de não-ortogonalidade. As quinas são construídas em um jogo ilusionista de trompe-l'oeil, de sorte que, ao percorrer o espaço, é possível obter tal situação. Na tentativa de buscar um novo equilíbrio, quem experimenta o espaço é obrigado a caminhar, vivenciar o ambiente, quebrar certezas sobre si mesmo e sobre o mundo.

Malhas da liberdade (1976) retoma a indagação sobre o espaço de Cantos, apostando na libertação do ilusionismo pictural ao conduzir a linha ao seu sentido originário. Em uma pintura com figura e fundo, as linhas e desenhos estão como reféns das leis da perspectiva clássica, engendrando um espaço ideal fora do mundo. Nessas Malhas da liberdade, as estruturas em ferro que se sobrepõem não se limitam, caminham para o infinito. Grade que se espalha em um plano, essa composição também ganha volume. Aqui, a ideia é trabalhar com princípios formadores, constituintes, livres de limitações formais. Trata-se de constantes que possibilitem "a passagem de uma estrutura a outra, em qualquer ponto do tempo e do espaço". (CAMERON, 2000) Um retângulo de vidro transparente sentencia a impossibilidade de um fundo, de um espaço privado. Não há duplo, o espaço se apresenta nele mesmo.

Eureka / Blindhotland (1970) joga com a falibilidade de nossa percepção. Nossos sentidos podem nos trapacear, ele nos diz. O trabalho propõe que cinco cubos de madeira possam ter o mesmo peso de seis cubos idênticos. Na verdade, em um dos cubos há um pedaço de chumbo que faz com que os dois pratos de uma balança se equilibrem. Fomos ludibriados pelo peso de chumbo no interior da obra, espaço inacessível e privado. O engano deve-se à crença em uma lógica ordenada anteriormente à experiência. Disposta em formato de uma cruz, a primeira barra de madeira lembra o sinal " $X$ " da operação matemática, enquanto a 
segunda assemelha-se ao sinal de igualdade da notação aritmética. A disposição inclinada da cruz ao lado das barras paralelas altera visualmente a percepção, fazendo com que se oscile, ao buscar identificar esses sinais, entre uma cruz e o sinal "mais" da operação aritmética. Nossa percepção contradiz as ideias estabelecidas nessas formas. Acreditamos no que percebemos ou no que presumimos como verdade? É nesse momento da experiência que somos convidados a verificar as verdades fundadas em lógicas anteriores à experiência. Que um registro gráfico seja uma cruz ou um sinal da operação matemática depende fundamentalmente de nossa percepção, da experiência instaurada por um "corpo pensante" da fenomenologia, reorganizando um saber desse momento que constitui o mundo.

Em Eureka, duzentas bolas de borrachas do mesmo tamanho e cor estão espalhadas na área estipulada para o trabalho, adensando a impressão de movimento e oscilação causada pelas barras de madeira. Nesse registro, o olho vaga pelos diversos pontos indicados pelas bolas, sem conseguir apoiar-se em um único referencial. O contato com pontos difusos pulveriza uma possível identificação do corpo com um ponto convergente, embargando a formação de um eu centralizado e subjetivo. Ao transgredir a distância entre sujeito e objeto, torna-se possível a construção de um espaço no qual o significado articula-se no espaço da experiência no mundo.

Ao pensar o trabalho de arte que revele seu significado no real, Cildo Meireles elabora espaços escultóricos estruturados a partir do som. Em Mebs/Caraxia (1970-71), utilizando um sintetizador de frequência, o artista converte gráficos de uma fita de Moebius e uma espiral em registros sonoros. Tal como uma fita de Möebius em que a superfície exterior está em continuidade com sua superfície interna, na faixa Mebs do disco, um gráfico da forma da fita - logo, uma redução da concepção abstrata da fita a uma superfície exterior pública - forma um continuum com sua superfície interna ao converter a linguagem gráfica e externa em uma linguagem sonora. O mesmo procedimento é adotado na faixa Caraxia, em que a forma abstrata de uma espiral é reduzida a um gráfico e, posteriormente, sonorizada. Na fita ou anel de Moebius, o que está dentro está fora e o que está fora está dentro, o que cria uma superfície contínua onde finito e infinito são uma coisa só. Inserções em jornais (1969-70) insere uma combinação de elementos diferentes e separados, alternando suas posições em oito diferentes jornais do Rio de Janeiro, de modo a criar um continuum visual que se estabeleça não apenas em ou para um indivíduo, mas na soma desses indivíduos. 
Há precedentes da utilização da topologia da fita de Moebius na arte brasileira. Com o objetivo de privilegiar a experiência na obra de arte, artistas como Lygia Clark e Hélio Oiticica incorporaram a estrutura dessa fita em suas pesquisas. Pretendiam, assim, vivenciar novas relações espaço-temporais. Com sua proposição Caminhando (1963), Lygia Clark explorou os limites entre o objeto de arte e o mundo. A ideia era provocar uma mudança na relação do sujeito com seu ambiente: o objeto de arte é vivenciado no próprio ato de produzi-lo, evitando-se assim a separação entre o homem e as coisas. Este espaço topológico também está presente no Parangolé de Hélio Oiticica. Aqui, Oiticica elimina a intermediação entre o espaço delimitado à obra de arte e o delimitado pelo espectador, de modo que significação, sempre precária, atualiza-se na pessoa que a veste e incorpora. Nas palavras do artista:

Está aí a chave do que será o que chamo de arte ambiental: o eternamente móvel, transformável, que se estrutura pelo ato do espectador, e o estático, que é também transformável a seu modo, dependendo do ambiente em que esteja participando como estrutura. (CLARK, 1986)

Nas propostas de Lygia Clark e de Hélio Oiticica, a ideia de participação guarda o sentido de uma transformação radical entre artista, trabalho e espectador. Assim, participar seria a elaboração em conjunto do trabalho, fazendo com que o conhecimento se dê ao mesmo tempo de sua elaboração. Os participantes podem "vivenciar" a proposta, desvelando, no momento mesmo do ato, o significado do trabalho. Situação semelhante ocorre na fita de Moebius; não é preciso escolher entre a interioridade e exterioridade, antes ou depois, pois o processo é simultâneo.

As experiências de espaço promovidas pelas propostas de Lygia Clark e de Hélio Oiticica encontraram chancela teórica na filosofia fenomenológica. O espaço da obra não se restringe àquele isolado por uma moldura ou um pedestal. Diferentemente, ao romper tal noção de autonomia passa a incorporar um conjunto de vivências intensamente experimentado pelo espectador. Ao incorporar o espaço vivencial do participante, a obra deixa de estar no espaço para ser no espaço, ganha qualidade de corpo. Dialogando com tal legado, o espaço em Cildo Meireles é pensado como um campo contínuo entre objeto e contexto, entre arte e mundo. Constata-se, entretanto, uma diferença na obra de Cildo Meireles. A influência do pensamento de Duchamp permitiu a radicalização das pesquisas de arte que tentavam pensar o objeto. Como linguagem, os trabalhos de Meireles afastam-se de uma noção de subjetividade 
tradicionalmente impregnada no processo de significação do objeto artístico. Tal abordagem permitiu a eliminação da categoria da "expressão" ainda presentes nas obras dos artistas neconcretistas. No entanto, sua obra guarda algo da experiência sensível com os objetos. Seria possível mesmo perceber em sua obra, caracterizada pela reflexão do conceito de objeto de arte, o que era vivido em outros países com a preponderância da racionalidade própria das correntes artísticas conceituais, uma solicitação da experiência, uma fenomenologia característica recorrente na arte moderna e contemporânea brasileira, que em Cildo Meireles encontra-se mediada por um sistema de linguagem.

\section{Desvios cromáticos}

Nas investigações de Cildo Meireles, a noção de espaço pode vir a ser reavaliada por meio da saturação cromática. São trabalhos como Desvio para o vermelho (1967-1984), Fontes (1992), Cinza (1984-1986), Marulhos (1991-1997), em que a cor atua como elemento perturbador da ordem. Aqui, a cor é apresentada em sua potência máxima, encaminhando a experiência a uma situação-limite, a ponto de desnaturalizar o espaço. Desvio para o vermelho é um dos trabalhos monocromáticos em que Meireles elucida sua proposta de reavaliação do espaço fazendo uso da cor: três ambientes dispostos em um continuum - Impregnação, Entorno, Desvio - nos convidam a viver o vermelho em sua mais alta potência. Impregnação é o nome dado pelo artista ao primeiro ambiente e também é a designação de um fenômeno no campo ótico da Física. A impregnação como fenômeno físico é a tendência das ondas luminosas a se desviarem (na refração) para aquela de maior extensão, a vermelha. Aqui, mais uma vez, Meireles encontra no traspasse da ciência a solidariedade conceitual para a construção de sua mitologia poética.

Imersos na cor vermelha, tal ambiência cria uma situação inesperada, uma visão quase planar que nos inicia em uma nova relação com a obra. Nesta situação, o olho está entregue à própria sorte, condenado a vagar em busca de um ponto de apoio, de estabilidade. Esforço vão... Uma vez livre das referências narrativas, a cor estrutura o espaço. O vermelho invade o espaço a ponto de constituí-lo. Em uma intensidade inimaginável, o vermelho incita nossa percepção a pulsar em seu grau absoluto. Diferencia-se assim de uma certa normalidade do cotidiano, reaparece como estranhamento. A impregnação cromática do espaço encontra antecedentes 
no Atelier Rouge (1911) de Matisse, no qual a presença absoluta da cor vermelha na tela estrutura o que seria uma nova concepção de espaço a partir da inteligência cromática.

Em Impregnação, encontramo-nos imersos em uma sala de estar em que todos, absolutamente todos os objetos são vermelhos. Quadros de amigos artistas, móveis, livros, pequenos objetos, rastros de história pessoal dão origem, simultaneamente, à atmosfera de afetividade e à opressão dos ambientes domésticos. Carmim, escarlate, escuro, claro, o vermelho percorre todo o espectro de matizes, oscilando entre o polo das pequenas alegrias e afabilidades e o da sensação de imobilidade, da paralisação da corrente de ar. Como se aqui fosse o habitat do cidadão médio que, segundo Kathrin Rosenfield, é sugerido no Le grand verre de Duchamp. O homem, esmagado "pela sofisticação da 'máquina' racional, capaz de transformar o que há de pior na humanidade - o homem médio, covarde, acanhado e submisso - em forças sociais". (KATHRIN, 1996)

Prosseguindo no fluxo do trabalho, adentramos no Entorno em que, no chão, uma enigmática garrafa entorna quantidade desmesurada de líquido vermelho desproporcional ao seu minúsculo tamanho: subversão da relação dentro e fora, continente e conteúdo. É a cor invadindo a materialidade do campo-chão, livre das injunções de preenchimento da forma. Em Entorno, o estranhamento do primeiro ambiente se intensifica. As paredes vazias, o foco no campo horizontal do solo não permitem que reconheçamos nosso corpo em nenhum ponto. Não há onde espelhar uma suposta subjetividade de nossas sensações. A imagem que temos de nós, sujeitos divorciados do mundo, é abalada. Resta-nos, assim, a alternativa de deixar o corpo habitar o trabalho em busca de novas significações. Aqui, somos levados a romper com uma atitude descorporificada da carne da vida; estamos no vermelho. Tal como em Impregnação, o vermelho invade o espaço a ponto de constituí-lo. O líquido escorrendo da garrafa de vidro parece formar um contínuo ininterrupto com a exterioridade, como se o movimento de saída e entrada, interior e exterior fosse um só. Uma vez instalados no vermelho, somos este incessante movimento. Mas o vermelho, nesse caso, é fundamentalmente "desvio", interrompe a ordem, transtorna o modo como entendemos no mundo.

Em Meireles, os desvios que podem ser cromáticos, semânticos, espaciais ou materiais, apenas para citar alguns, dizem respeito à própria redefinição de arte. É como se em sua 
investigação poética sobre o conceito de artista nos deparássemos com algo próximo à ideia de real pela psicanálise do real; como aquilo que não se entrega à ordem e não cessa em retornar ao momento em suspenso de seu lance inicial.

Não por outro motivo, as ideias de passagem, como em Malha da Liberdade, de atravessamento em Através (1983-1989) são uma constante em sua obra, pois em tais experiências podemos nos perder para nos achar em outros termos. Em Através, indícios de restrição de locomoção, redes de pesca, cercas de pasto, pedaços de voal, venezianas, cercas de jardim, portões de madeira, grades de prisão, cercas de ferro, mosqueteiros, barreiras policiais, arames farpados, redes para quadra de tênis, provocam o efeito semelhante de estarmos perdidos em uma teia, de estarmos dando voltas sem um caminho certo. A obra enseja o desafio de estarmos à deriva, pois só quando perdemos o mundo é que começamos a nos encontrar e a perceber onde estamos, e a extensão infinita de nossas relações. (CAVELL,1997) Em última análise, o artista proporia que, a partir da perda de nossas certezas, seria possível dar início à nova relação de construção entre a obra, o sujeito e o mundo. No limite, "a poética do desvio" de Cildo Meireles declara que a arte é desvio, uma atividade transgressora cuja tarefa é a recolocação do real, a repontencialização poética da existência.

Recebido em 19/03/2017 e aprovado em 05/05/2017.

\section{Referências}

CAVELL, Stanley. Esta América nova, ainda inabordável. São Paulo: Editora 34, 1997.

CLARK, Lígia; OITICICA, Hélio. 9 Salão Nacional de Artes Plásticas, Paço Imperial, Rio de Janeiro, 13/11-21/12/1986 (catálogo de exposição).

DUCHAMP, Marcel. O ato criador. In BATTOCK, Gregory (org.). A nova arte. São Paulo: Perspectiva, 1975.

KATHRIN H. Rosenfield. T.S Eliot \& Charles Baudelaire: poesia em tempo de prosa. São Paulo: Ilumminuras, 1996.

KRAUSS, Rosalind. Caminhos da escultura moderna. São Paulo: Martins Fontes, 1998.

MEIRELES, Cildo. Inserções em circuitos ideológicos 1970-75. In HERKENHOFF, Paulo; MOSQUERA, Gerardo; CAMERON, Dan (orgs.). Cildo Meireles. São Paulo: Cosac \& Naify, 2000. 